\title{
Mathematics in assisting process planning in horticulture
}

\begin{abstract}
Experimentally obtaining products with optimal properties for a given application, in a trial and error approach, is an expensive and slow process. In this case, the use of mathematical and computational techniques to assist in realistic theoretical predictions serve as a guide for experimental procedures and contribute to saving time and resources. However, to facilitate the application of mathematical modelling, it is necessary to resort to simplifications, in such a way as not to lose the realism of the model to be formulated. Mathematical methods are important not only for aiding experiments but also to assist process planning in horticulture, for example, planning of the: management of the cultivation of flowers, fruits and vegetables; application of agricultural technologies; planting and harvesting aiming to increase productivity; soil preparation; installation of irrigation and drainage systems; application of compost and fertilizers; pest and disease management; among others. In this context, the main purpose of this paper is to show that mathematical models can be used as a tool to aid planning and decision making processes in Horticulture.
\end{abstract}

Keywords: mathematical modelling, applied mathematics, computational techniques, process planning in horticulture, optimization
Volume 4 Issue 2 - 2020

\author{
Camila de Lima, Helenice de Oliveira \\ Florentino \\ Department of Biostatistics, Plant Biology, Parasitology and \\ Zoology, Institute of Biosciences, São Paulo State University \\ (UNESP), Brazil
}

\begin{abstract}
Correspondence: Camila de Lima, Prof. Dr. Antônio Celso Wagner Zanin, Department of Biostatistics, Plant Biology, Parasitology and Zoology, Institute of Biosciences, São Paulo State University (UNESP), Distrito de Rubião Junior, CEP: |86 |8-689, Botucatu, São Paulo, Brazil, Tel +55|43880-0069, Email cla.slva@unesp.br
\end{abstract}

Received: March 07, 2020 | Published: March 17, 2020

\section{Realistic mathematical modelling}

Mathematical modelling is a relevant knowledge area that studies simulation of real systems in order to predict and understand its behavior. Simulations are developed from computational implementations of the mathematical description of the phenomena involved in the real system, i.e., from mathematical model. Mathematical models are extensively used in Engineering and science, such as Agriculture, Medicine, Physics, Chemistry, Biology, Economics, and others.

Mathematical model is a representation of system which exists in reality or which should emerge in reality, described with mathematical equations. Methodology of developing mathematical models (mathematical modelling) consists of several steps. ${ }^{1,2}$ The first step is the knowing about the real problem to be modeled. In general, in this step the mathematical modeler should be advised by a specialist knowledge area in which the real problem is inserted. The majority of interacting systems in the real world are far too complicated to model in their entirety, therefore, the modeler must to identify the most important part of the system to be included in the model and the rest is excluded, aiming to write the mathematical expressions with the minimal number of items and variables, decreasing the mathematical and computational complexity. In addition, the modeler must collect real and/or experimental data to be used as parameters of the mathematical model.

The next step is to identify the variables of the problem, from which the mathematical expressions will be constructed. The mathematical modeler must to know the required objectives of the model to be created, such as: to assist a given decision making (managements); to optimize a processes (maximize profit, minimize costs, minimize environmental impact, etc.); to obtain numerical estimates of determined element of the process (production, fuel consumption, number of machines, etc.), to understand the behavior of a process for a certain period of time (in order to reproduce or to understand the system, and/or apply control).

Depending on the purpose of the model to be created and type of variable defined (discrete, continuous, random, etc.), it is chosen a techniques to be used in the construction and resolution of mathematical model. This technique can involve Optimization Theory, Dynamic Systems (Differential Equations), Applied Statistics, Numerical Calculation, etc. ${ }^{3-5}$ Therefore, the mathematical model of the real problem is formulated using the mathematical knowledge.

After mathematical formulation and determination of the proper parameters value, the next step is the model resolution. For this purpose, mathematical and computational methods are used. There are several algorithms and computational software for solving mathematical models, which depend on the set of mathematical areas in which the model is inserted. After solving the model, it goes on to validation phase, where is verified if the model represents with fidelity the real process. After that, the model can be used to help in solving real problems.

\section{Contribution of mathematical model for the horticulture}

Horticulture production process is a highly complex system due to sowing, growth and harvesting processes, which can be affected by weather and soil conditions, appearance of insects and weeds, diseases contamination, and other factors. ${ }^{6}$ Moreover, the resource sustainability must be considered to ensure the harvesting rate of the resource without compromising its natural regenerative capacity. This system complexity is also justified by the relationship between of the production processes and environmental, economic, politics and social issues. ${ }^{7}$ In this context, mathematical modelling is a very useful tool, which permits describing, ${ }^{8}$ predicting ${ }^{9}$ and/or optimizing 
operational and production processes planning in order to assist the decision-making in horticulture aiming to increase crop yields and improve crop quality. ${ }^{10}$

Over the last decades, several mathematical models have been developed aiming improvement of planning process, mainly to determining optimal operational, tactical and strategic planning in many sectors of the Horticultural, such a land preparation, planting, crop cultivation, irrigation and drainage, use of machinery, diseases control, harvesting, etc. ${ }^{11-14}$ Currently, these mathematical applications have not been related only to the plants cultivation, they have been very wide, being applied throughout the horticultural supply chain. ${ }^{15}$ including to internal structure (financial situation, production and management) and external structure (technological developments, potential of species and cultivars, market, economy and environmental condition) of the horticulture, besides attending the environmental issues through sustainable cultivation ${ }^{16,17}$ and use of waste. ${ }^{18}$

The globalization of the economy has caused changes in the horticultural supply chain and enabled technological and structural advances. In this way, tools are necessary to help improve competitiveness, strengthen research and rural extension. In this context, the mathematical modelling is one of these tools that can help to enhance the improvement of the entire supply chain, guaranteeing its competitiveness and sustainability and promoting an activity inserted in horticulture of economic and social reach.

\section{Acknowledgments}

This study was financed by the Coordenação de Aperfeiçoamento de Pessoal de Nível Superior - Brasil (CAPES) Finance Code 001, CNPq (312551/2019-3) and FAPESP (2013/07375-0).

\section{Funding}

None.

\section{Conflicts of interest}

Authors declare no conflict of interest exists.

\section{References}

1. Hillier FS, Lieberman GJ, Nag B, et al. Introduction to operations research. 9th ed. New York: McGraw-Hill; 2012.

2. Venkateshan SP, Swaminathan P. Computational Methods in Engineering. 2nd ed. Academic Press, 2014.

3. Nocedal J, Wright SJ. Numerical optimization. 2nd ed. Springer Science \& Business Media, 2006

4. Raol JR, Girija G, Singh J. Modelling and parameter estimation of dynamic systems. 1st ed. IET Control Engineering Series. 2004;65.
5. Warner RM. Applied statistics: from bivariate through multivariate techniques: from bivariate through multivariate techniques. 2nd ed. SAGE, 2013

6. Solano NEC, Llinása GAG, Montoya-Torres JR. Towards the integration of lean principles and optimization for agricultural production systems: a conceptual review proposition. J Sci Food Agric. 2020;100:453-464.

7. Weintraub A, Romero C. Operations research models and the management of agricultural and forestry resources: a review and comparison. Interfaces. 2006;36(5):446-457.

8. Lentz W. Model applications in horticulture: a review. Scientia Horticulturae. 1998;74:151-174.

9. Logan TM, McLeod S, Guikema S. Predictive models in horticulture: A case study with royal gala apples. Scientia Horticulture. 2016;209:201213 .

10. Plà LM, Sandars DL and Higgins AJ. A perspective on operational research prospects for agriculture. Journal of the Operational Research Society. 2017;65(7):1078-1089.

11. Zaraté P, Alemany M, del Pino M, et al. How to support group decision making in horticulture: An approach based on the combination of a centralized mathematical model and a Group Decision Support System. In: Freitas P \& Dargam F, et al. editors. Decision support systems IX: Main developments and future trends. EmC-ICDSST 2019. Lecture Notes in Business Information Processing. 2020; 348.

12. Kea S, Guob D, Niub Q, et al. Optimized production planning model for a multi-plant cultivation system under uncertainty. Engineering Optimization. 2015;47(2):204-220.

13. Gary C, Jones J, Tchamitchian M. Crop modelling in horticulture: state of the art. Scientia Horticulturae. 1998;74:3-20.

14. Chilundo RJ, Maúre GA, Mahanjane US. Dynamic mathematical model design of photovoltaic water pumping systems for horticultural crops irrigation: A guide to electrical energy potential assessment for increase access to electrical energy. Journal of Cleaner Production. 2019;238:117878.

15. Zhu Z, Chu F, Dolgui A, et al. Recent advances and opportunities in sustainable food supply chain: a model-oriented review. International Journal of Production Research. 2018;56(17):5700-5722.

16. Aliano Filho A, Florentino HO, Pato MV, et al. Exact and heuristic methods to solve a bi-objective problem of sustainable cultivation. Ann Oper Res. 2019.

17. Cotler H. Paths towards sustainable agriculture. Horticulture International Journal. 2019; 3(4):206--207.

18. Wei L, Li X, Yang W, et al. Optimization of operation strategies of a syngas-fueled engine in a distributed gasifier-generator system driven by horticulture waste. Energy Conversion and Management. 2020;208:112580. 